\title{
José Vasconcelos. Diferencia y continuidad del proyecto de nación
}

\author{
Martha Cecilia Calderón Pichardo
}

\section{Resumen}

El proyecto de nación propuesto por Vasconcelos no se agota únicamente en la comprensión políticohistórica de su momento ni en su aportación educativa. En el presente artículo se expone la importancia del proyecto cultural y artístico de Vasconcelos y la relación intrínseca con su propuesta política y educativa, tomando como caso de estudio la Escuela Mexicana de Pintura.

Palabras clave: Vasconcelos, Ateneo de la Juventud, Escuela Mexicana de Pintura, arte.

\section{Jose Vasconcelos. Difference and continuity of the nation Project}

\begin{abstract}
The project of nation proposed by Vasconcelos is not only exhausted in the political-historical understanding of its moment nor in its educational contribution. This article aims to expose the importance of the cultural and artistic project of Vasconcelos, the intrinsic relation with his political and educational proposal, taking as a case study the Mexican School of Painting.
\end{abstract}

Key words: Vasconcelos, Ateneo de la Juventud, Mexican School of Painting, art. 


\section{Martha Cecilia Calderón Pichardo}

cecilia111@hotmail.com

Artista e investigadora egresada de la Escuela Nacional de Artes Plásticas de la Universidad Nacional Autónoma de México (UNAM). Es docente de educación artística e historia del arte a nivel licenciatura en la Facultad de Artes y Diseño de la UNAM. Actualmente estudia la licenciatura en Filosofía en la Facultad de Filosofía y Letras (FFyL) de la misma universidad. Sus áreas de interés son la estética y el arte contemporáneo. Su obra plástica ha sido publicada en la Gaceta UNAM y en el periódico Excelsior.

\section{Introducción}

Cuando se habla del pensamiento de José Vasconcelos se pueden ver dos etapas de su vida. Por un lado, sus inicios como estudiante en donde se atienden, con cierto tono de romanticismo, las crónicas en las que recuerda a los jóvenes que, por amor y gusto al conocimiento, decidieron formar el Ateneo de la Juventud. Por otro lado, a un Vasconcelos maduro que participa activamente en la vida política mexicana hasta obtener diferentes cargos en el gobierno posrevolucionario.

En ambos casos, el pensamiento de Vasconcelos muchas veces se considera subordinado al contexto político y sólo se recupera la trascendencia de sus ideas en lo educativo. Sin embargo, se debe estudiar a este personaje desde su propio pensamiento y al mismo tiempo relacionar el contexto político, social y cultural que lo enmarcan. De esta manera, se podrá advertir el cambio y la transformación de éstas áreas a partir de sus ideales.

El objetivo de este trabajo es analizar la repercusión cultural que tuvo el pensamiento de Vasconcelos en el país y las artes. El análisis parte de una revisión documental de fuentes teóricas y asociación con eventos históricos, tomando el caso particular de la Escuela Mexicana de Pintura. Dicha institución tuvo la influencia de Vasconcelos y heredó su pensamiento (a pesar de que con el tiempo fue tomando su propio camino hasta convertirse en una propuesta distinta), lo que permitió extender el campo de consecuencias y derivaciones de su pensamiento, más allá de la época posrevolucionaria y el ámbito educativo. 
Figura 1.

José Vasconcelos en su juventud, al egresar de la Escuela Nacional de Jurisprudencia (ca. 1907). Fuente: Discurso del maestro.

\section{El Ateneo de la Juventud}

Vasconcelos, como miembro del Ateneo de la Juventud, expresaba que "solamente la filosofía cuenta con una tradición de pensamiento selecto; sólo el pensamiento filosófico que abarca a la vez los tres problemas — la sensibilidad, el intelecto y la moral - ha podido subsistir sin interrupciones de importancia, a través de los siglos, renovándose constantemente en escuelas y en sistemas siempre fecundos" (Vasconcelos, 2000: 13). Es por esta razón que sus proyectos, a pesar de estar inscritos en un contexto político particular, no se pueden desvincular de la propuesta filosófica integral a la cual aspiraba; para Vasconcelos todo proyecto educativo debe tener como punto de partida una filosofía (Bernal, 2006).

El Ateneo de la Juventud criticaba el positivismo y buscaba una educación humanista, una apertura cultural, que permitiera la preparación más integral y libre. El interés del Ateneo y de Vasconcelos por hacer énfasis en lo cultural se vio reflejado en la creación de la Universidad Popular Mexicana, que se convirtió en una de las primeras evidencias de la Revolución en el país. Sin embargo, con la dispersión de los miembros del Ateneo de la Juventud por el proceso revolucionario, no se pudo continuar con el proyecto de fundar instituciones y de tener maestros para el pueblo; en la etapa postrevolucionaria solo se identifica a José Vasconcelos y a Alfonso Reyes (Curiel, 2001).

El proyecto de los ateneístas de enriquecer la cultura mexicana y regenerar la sociedad continúa en

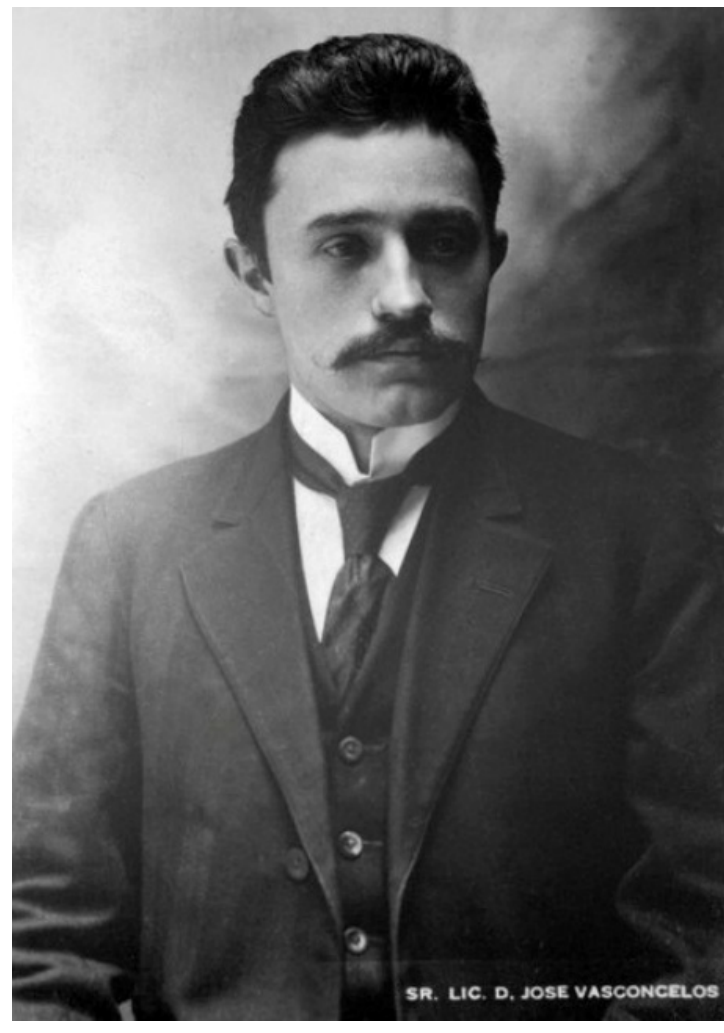
1912, cuando Vasconcelos es elegido presidente del Ateneo de la Juventud y propone fomentar las humanidades y la cultura. Fernando Curiel relata que el "momento culminante de la vinculación Ateneo-Siete Sabios será el vasconcelismo cultural y educativo de 1920-1924. Primero en la Universidad Nacional de México, y acto seguido, en la Secretaría de Educación Pública, llevando a la práctica el programa del Ateneo" (2001: XXII). 


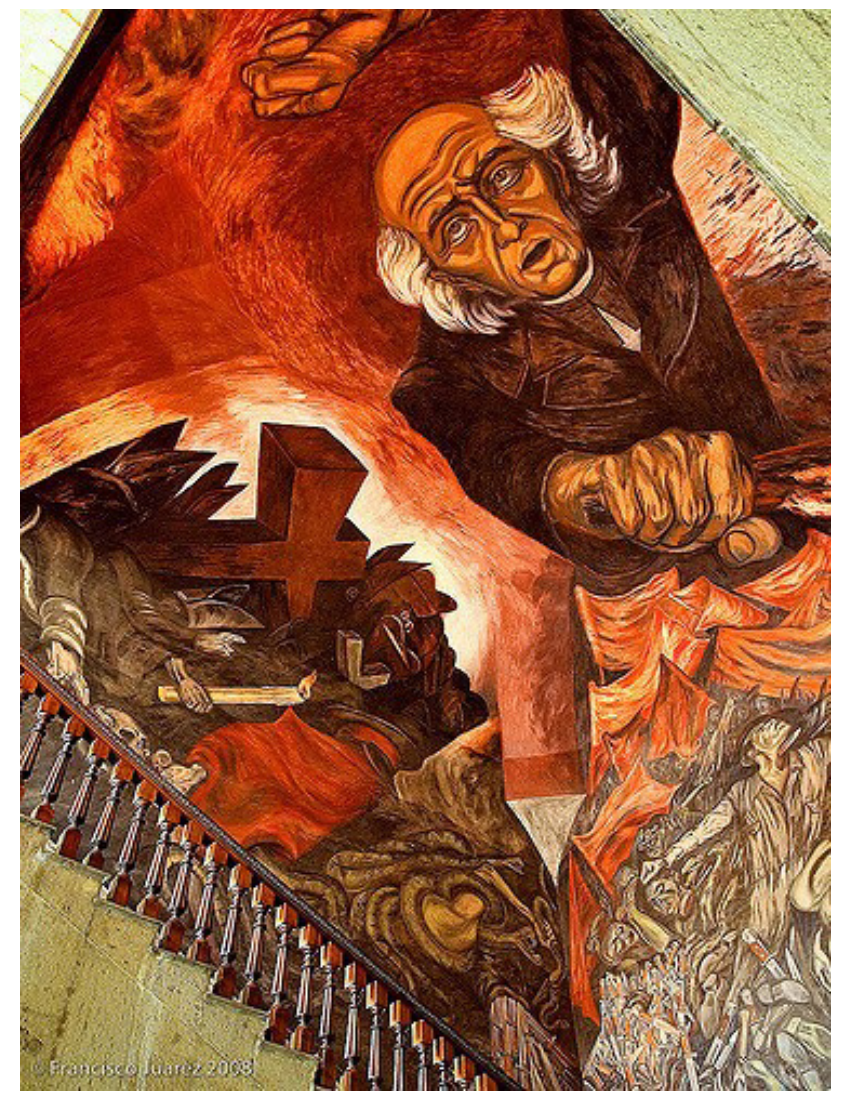

Figura 3.

Hidalgo, José Clemente Orozco, Palacio de Gobierno, Guadalajara.

Fuente:

Francisco Juárez.

1. Pinturas de José María Velasco, en donde se ve de nuevo la ironía, debido a que era un pintor en estrecha relación con Porfirio Díaz. peleado en la Revolución. Este tipo de difusión de lo nacional sustentado en lo popular también fue promovido por la Escuela Mexicana de Pintura. Aunque en principio la encomienda de Vasconcelos fue mostrar la historia de las revoluciones, por convicción de los propios artistas se terminó mostrando un orgullo por las raíces indígenas, lo popular y las tradiciones.

Diego Rivera fue quien tuvo mayor interés por formar el imaginario colectivo de la identidad nacional a partir de una manifestación artística que fuera empática desde sus valores estéticos con los grupos marginados socialmente, trabajadores e indígenas. En el caso de los trabajos de Siqueiros y Orozco (ver figura 3) éstos estuvieron más enfocados a la crítica social y política a través de sus obras. Algunas de estas pinturas fueron difundidas por Vasconcelos en los libros de texto gratuitos para promover masivamente una imagen heroica de la Revolución, valores compartidos, tradiciones, el paisaje nacional ${ }^{1}$ y un sentido de pertenencia a una raíz ancestral.

[...] los presentes de las sociedades, pueden ser tan disgustantes que, siempre ha sido costumbre de poetas buscar alivio en las leyendas de pasados mejores, y afición de sabios remitir a la esperanza del porvenir, ya sea este consuelo un engaño de las fuerzas que mantienen la vida terrestre o bien porque un instinto presagia que realmente guarda algo el porvenir en una entraña misteriosa (Vasconcelos, 1916).

Este sentimiento de angustia frente al porvenir después de una Revolución, fue plasmado en dos sentidos en su proyecto cultural: un país que se integraba al desarrollo internacional con una cara nueva, pero que a su vez retornaba lo prehispánico para cimentar su identidad. De ahí que esta doble lectura de un país renovado pero ancestral quedara plasmada en la Escuela Mexicana de Pintura.

La imagen que se manejaba dentro del país era de desarrollo y un mejor porvenir, fundado en lo indígena como elemento unificador de todas las clases sociales. Esta difusión por parte del gobierno, de Vasconcelos y de la Escuela Mexicana de Pintura logró insertar el tema de lo indígena dentro de las reflexiones y gustos de la esfera intelectual y artística mexicana de manera que llegó a ser afín a la "alta sociedad" y se convirtió en moda, sustituyendo los valores de miseria atribuidos a lo indígena por valores artístico-culturales. A pesar de que esto, la valoración de lo indígena nunca atendía las necesidades sociales reales de ese sector de la sociedad. Por otra parte, elevar la producción popular a "arte popular" permitió convertir estos productos en objetos coleccionables, que dejaban atrás la necesidad de estéticas europeas. 
2. Por ejemplo, la cerámica de Tonalá y la joyería de Taxco.
Otro proyecto que Vasconcelos promovió dentro de la Secretaría de Educación Pública fue la incorporación, en 1923, de un método de dibujo (método Best Maugard) en los libros de texto de las escuelas públicas del entonces Distrito Federal. Tenía el objetivo de difundir un arte "auténticamente mexicano" y estandarizar la producción de arte popular para consolidar una imagen artística nacional. Muchos de estos diseños y dibujos del método Best Maugard son los que aún hoy conforman las manifestaciones de arte popular más características del país. ${ }^{2}$ Es ahí donde podemos observar parte de las repercusiones contemporáneas del pensamiento de Vasconcelos hecho proyecto.

Como puede observarse, la dimensión formativa cultural del proyecto de educación estética vasconceliana se cimentó en las raíces mexicanas y en un área de oportunidad, hasta ese entonces, ignorada. Tal proyecto fue promovido de forma integral y buscó generar un cambio de mentalidad en la manera de concebir el arte, no sólo entre los educadores, sino en la población en general (Bernal, 2006: 69).

\section{Filosofía y educación}

El proyecto cultural de Vasconcelos tanto en lo educativo como en lo artístico, no fue un proyecto simplista, pues estuvo impregnado de su pensamiento filosófico que se vislumbraba desde la época del Ateneo de la Juventud.

Vasconcelos tuvo como objetivo formar una conciencia de lo mexicano, aun cuando esto implicara crearla. Este interés de renovación se observa en su siguiente declaración:

Probablemente muchos de ustedes juzgarán reprobable todo este empeño de cambiar bruscamente las bases ideales de un pueblo. Yo me atreveré a decir que es ventaja de los pueblos jóvenes el poder prestarse a las experimentaciones más atrevidas... (Vasconcelos, 1916).

Vasconcelos pensaba que cuando un país no tiene bases firmes de identidad, fácilmente cambia de postura política, religiosa, filosófica o estética según el gobierno que esté en el poder. Por lo tanto, era necesario establecer bases independientes de la política que no cambiaran tan fácilmente y donde se pudieran desarrollar proyectos. Esta reflexión deriva del proyecto de la Reforma que él considera interrumpido una vez iniciada la política positivista de Porfirio Díaz y Gabino Barreda.

En su propuesta educativa el componente emocional era prioritario, y la educación estética era el medio adecuado para hacerlo. La razón era que las obras de arte incluían aspectos sensibles y emotivos, manifestaciones de discernimiento lógico, de intuición, de reconocimiento y de asociación. En toda vivencia estética siempre hay una referencia emocional y racional, aspectos psicológicos y sociales privativos del ser humano que merecen la pena de ser educados (Savín, 1972: 142). 


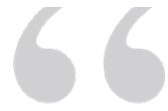

Las imágenes monumentales claramente tenían una función social, política y educativa implícita.

Es por esta razón que su proyecto educativo y artístico fue tan importante. Con la educación no sólo se logró alfabetizar gran parte del país, también se logró difundir una misma historia, imagen y esperanza de porvenir a nivel nacional. Al ser una educación adquirida en la niñez difícilmente podría ser olvidada o suplantada por otro tipo de concepción nacional. Tanto en éste proyecto, como en su labor como Rector de la UNAM, Vasconcelos retomó y desarrolló las ideas sobre educación cultural del Ateneo y el proyecto inconcluso de la Universidad Popular Mexicana.

Una de las principales fuentes de inspiración de Vasconcelos fue Anatoly Lunarchasky, comisario de Bellas Artes en la Rusia Soviética, del cual retomó varias apreciaciones: la idea de que un pueblo empieza a ser civilizado cuando se convierte en creador; de que el arte es para todos; de la importancia de acercar a los trabajadores la cultura, y de utilizar el arte del pasado para formar el proletariado culto, recurriendo a las raíces y la tradición como elementos de formación de identidad cultural (Bernal, 2006).

De esta manera, las imágenes jugaron un papel muy importante en la conformación de la identidad nacional y en el proyecto de nación de Vasconcelos, pues éstas llegaban más rápido y más directo al imaginario del pueblo mexicano que la ideas, además, los artistas supieron cómo transmitir el mensaje político y nacional a través de manifestaciones con las que las personas se identificaban.

\section{Escuela Mexicana de Pintura}

La Escuela Mexicana de Pintura fue un caso excepcional de pintura con contenido político a favor de las clases trabajadoras o grupos segregados. Diego Rivera menciona casos en Europa donde observó los fracasos del arte revolucionario que los gobiernos estaban implementando para las masas. El fracaso no se debía a que las obras fueran malas, sino a que se quería transmitir un mensaje revolucionario a partir de expresiones de arte burgués que resultaban ajenas e incomprensibles para la sociedad en general. Diego Rivera consideraba que era necesario tener un acercamiento directo con las tradiciones estéticas de las clases trabajadoras para poder retomar esos elementos y hablar en el mismo lenguaje. Cuando Diego Rivera, con la invitación de Vasconcelos, pudo implementar sus ideas sobre el arte revolucionario logró mostrar el éxito de su enfoque para captar la atención de la sociedad (ver las figuras 4 y 5). 
Figura 4.

Balada de la Revolución, Diego

Rivera, 1928, Secretaría de

Educación Pública, Ciudad de

México. Fresco 2.03 × 3.98 m.

Fuente:

Shannon.

Figura 5.

La epopeya del pueblo mexicano, Diego Rivera, 1935, Palacio Nacional, Ciudad de México.

Fuente:

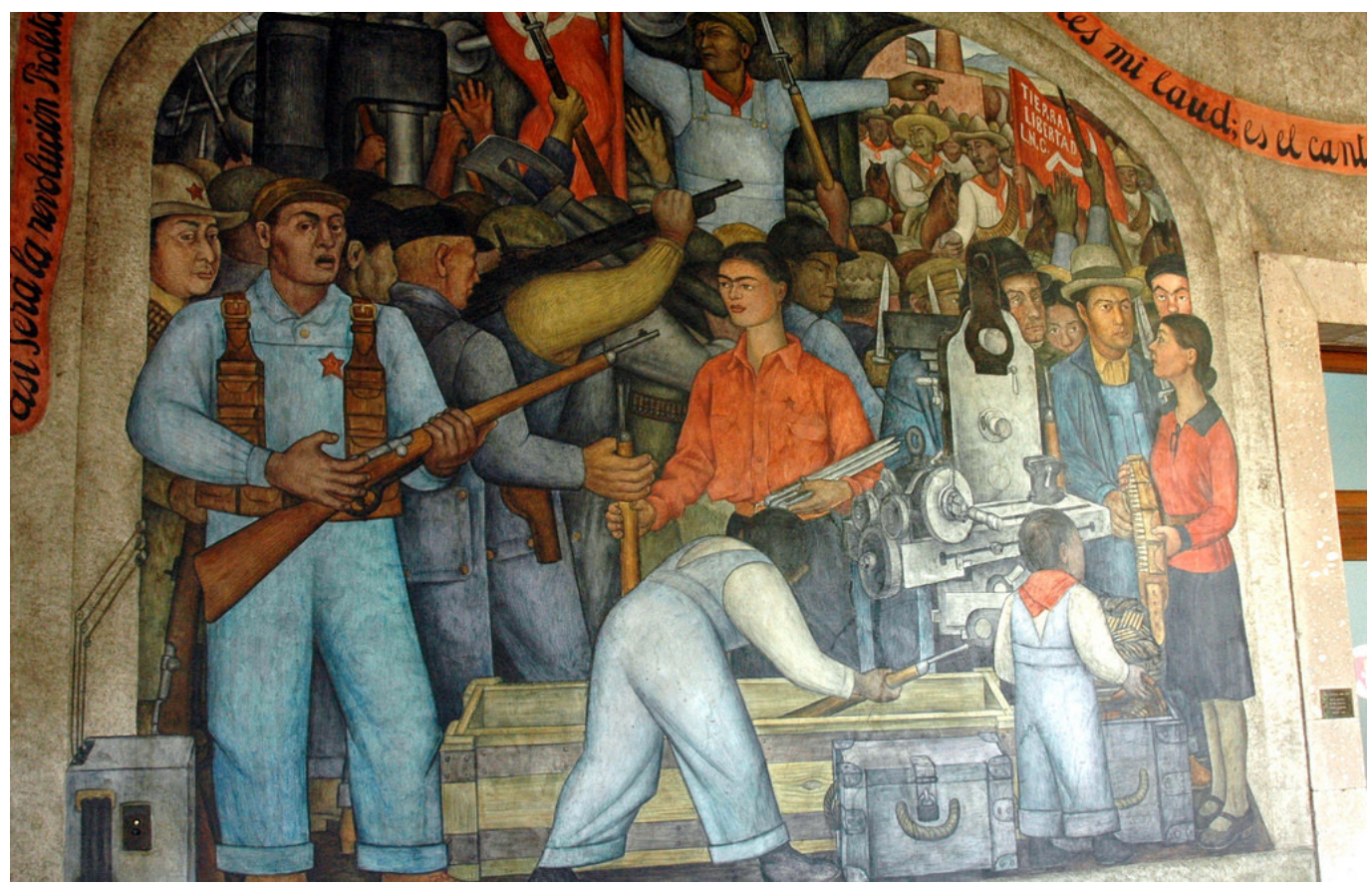

T) DeGroat.

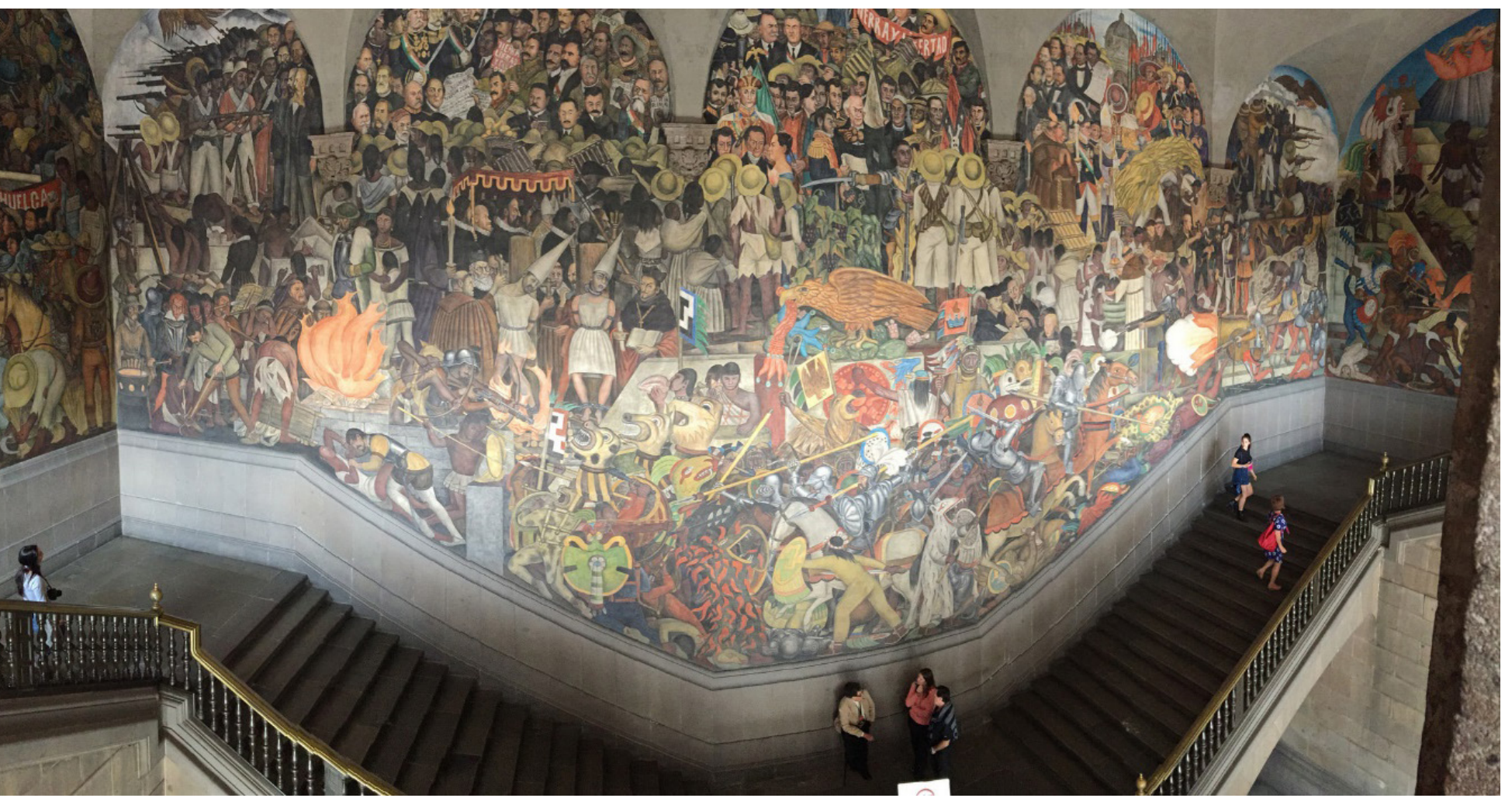


Figura 6.

El hombre controlador del universo, Diego Rivera, 1934, fresco sobre bastidor metálico

transportable, Museo del Palacio de Bellas Artes, INBA.

Fuente:

Wikipedia.

Estos hechos cambiaron por completo la visión que se tenía del arte mexicano en el mundo, porque fue hasta ese momento que se le reconoció a México tener un arte propio. Las obras de este período tenían dos lecturas, por un lado, era la legitimación de un país y de una sociedad que lograba tener manifestaciones artísticas propias como evidencia de ser una civilización compleja y consumada; por otro lado, mostraban un país culturalmente atractivo que atraía inversión y turismo.

La Escuela Mexicana de Pintura es un caso especial por la utilización del gran formato en las pinturas. Las imágenes monumentales claramente tenían una función social, política y educativa implícita. Vasconcelos declaraba: "Comenzaremos por la imagen para explicar la transformación del mundo senso-intelectual-ético en estético. La imagen es el comienzo de la estética porque mientras la idea representa la parte formal de la realidad, ella representa 'el sentido sobrenatural de la realidad"' (Vasconcelos citado en Carreras, 1970: 303).

Las obras de la Escuela Mexicana de Pintura tuvieron tal éxito que aún hoy son un atractivo turístico que retrata la cultura del país; representan la imagen que los propios mexicanos tienen del arte, e incluso en el ámbito artístico constantemente se retoman los temas nacionalistas, ya sea para exacerbarlos o para criticarlos, pero son obras profundamente vigentes y que no han sido superadas, aun cuando ciertas tendencias artísticas las consideren anacrónicas.

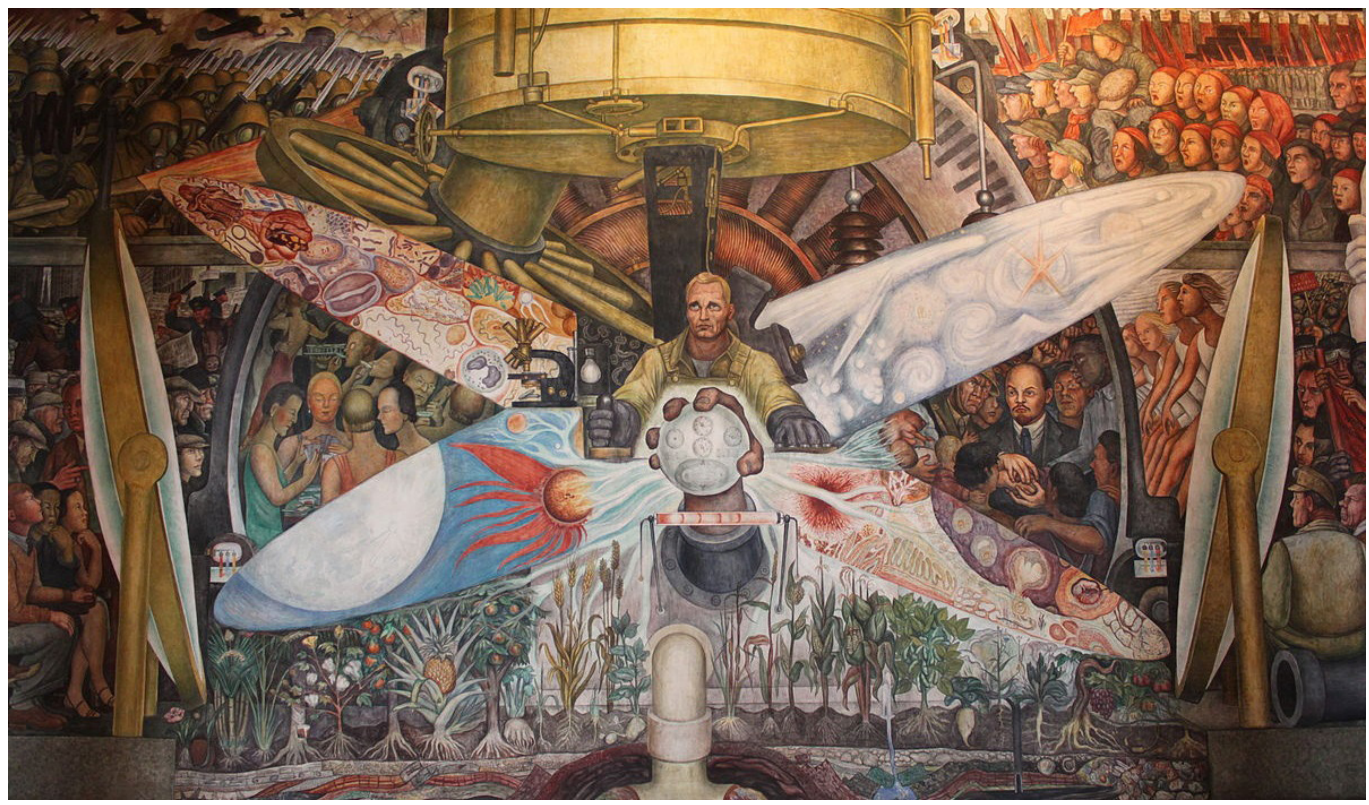

Las artes tienen un influjo directo en la vida cotidiana de las personas y para Vasconcelos era importante llevar lo artístico a todos los niveles de la sociedad, por ello fomentaba su encuentro mediante el impulso que da a la gastronomía, la moda, la decoración de edificios (casas y lugares de trabajo), el fomento de las artesanías, del folklore mexicano y de los festivales al aire libre 
Figura 7.

Abrazo, Diego Rivera, Palacio Nacional, Ciudad de México.

Fuente: Wikipedia. como medio de diversión y esparcimiento. Además, para reafirmar la difusión de ese imaginario político salieron un sinfín de productos de uso común, desde los calendarios, novelas y propaganda. Sin embargo, no descuidó la música, la pintura, el dibujo, la literatura y la danza (Bernal, 2006: 75).

De esta manera, el alcance del pensamiento de Vasconcelos, traducido en sus proyectos, sigue presente gracias a su concepción de la filosofía como un proyecto integral, que necesariamente debía incluir lo cultural y cuyas ideas supo transmitir a los sectores mayoritarios de la sociedad. Vasconcelos pensaba que "las grandes transformaciones de los pueblos determinan un violento impulso hacia adelante en que coinciden el despertar moral, la rebelión política y la renovación de las ideas" (Vasconcelos en Caso, 1962).

La Escuela Mexicana de Pintura tenía como objetivo la creación de un arte pedagógico con contenido político que difundiera valores nacionales. Diego Rivera pensaba que sólo cuando el proletariado lograra tener una sensibilidad propia —independiente de la burguesa - que le permitiera desarrollar su contenido estético de acuerdo a sus intereses económicos, se habría logrado la revolución cultural (ver figura 7).

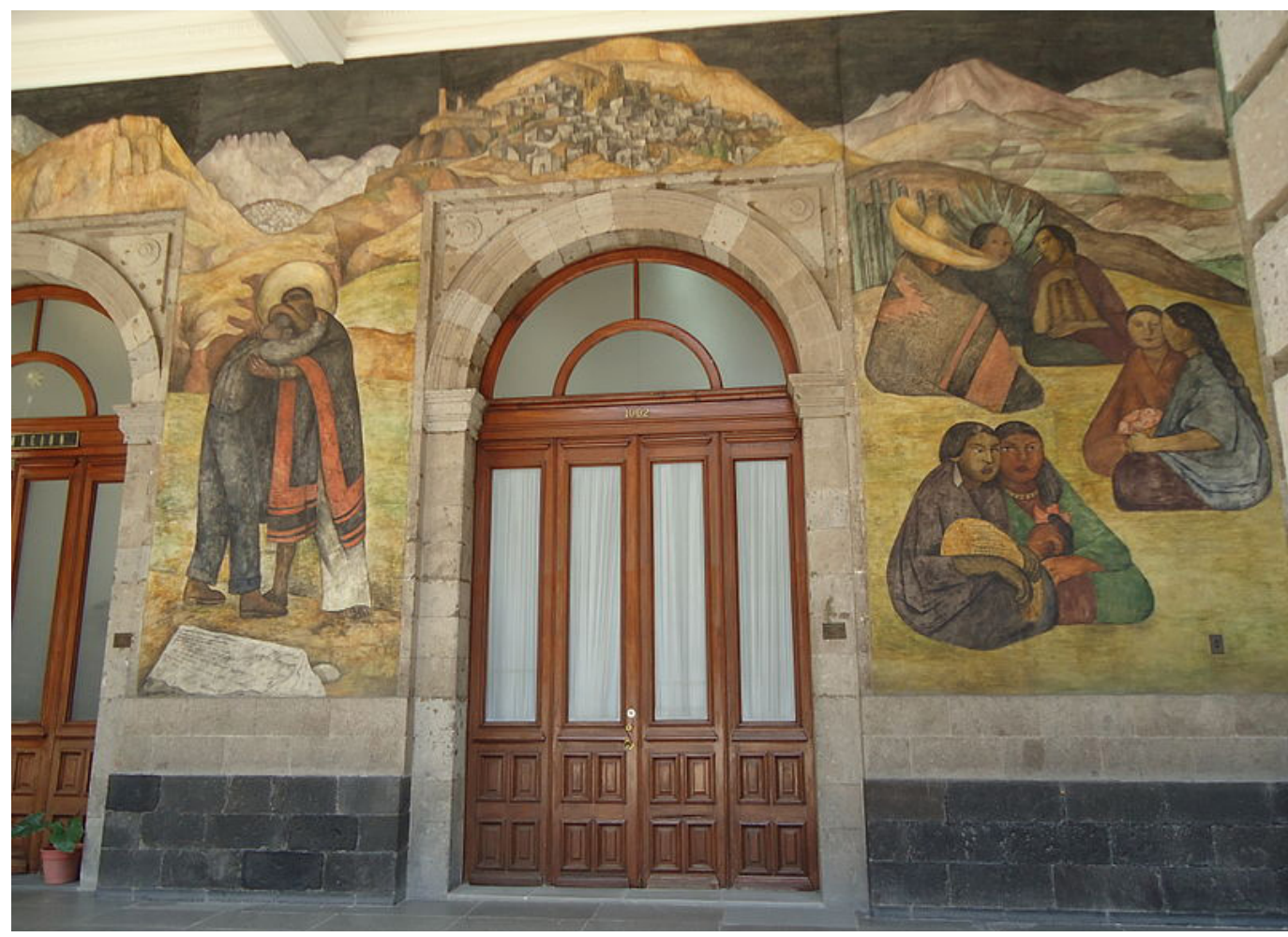

Vasconcelos buscaba, mediante la educación, que los seres humanos vivieran rectamente, hicieran justicia a la realidad y fueran capaces de actuar libremente expresando en ello su propia y original forma de ser. Dicho de otro modo, buscaba que aprendieran a conducir su vida sin dejarse llevar irracionalmente, 
que salieran del encierro de sí mismos y conocieran a fondo la realidad que les rodea. Es en este sentido que la educación, como proceso de mejora personal y permanente, prepara para la vida e incide directamente en la transformación de la sociedad (Bernal, 2006: 21).

\section{Conclusión}

Vasconcelos junto con el Estado llevaron a la práctica una ambiciosa renovación educativa y artística en la que estuvieron involucrados muchos artistas que aportaron sus propias ideas, su propia concepción del arte y la educación. Sin embargo, fue el pensamiento filosófico detrás del proyecto el que permitió plantearse el objetivo y fueron los artistas los que lo difundieron y materializaron.

Es por esta razón que no se debe leer a Vasconcelos únicamente desde el contexto político, hay que tratar de seguirle la pista en sus proyectos y en las consecuencias que derivaron de éstos, pues es en ellos que se plasma su pensamiento y que podemos valorar el alcance que tuvieron sus propuestas. Las aportaciones de Vasconcelos no se pueden estudiar sin tomar en cuenta su influencia en el ámbito artístico, los éxitos y alcances que tuvo su proyecto en esa área, así como por la propia vinculación con lo cultural y el enfoque filosófico integral que manifestó desde el Ateneo de la Juventud y en la Escuela Mexicana de Pintura.

Figura 8.

El pueblo a la universidad, la universidad al pueblo, David Alfaro Siqueiros, 1952-1956, junto a la torre de Rectoría de la UNAM.

Fuente: Mr. Theklan.

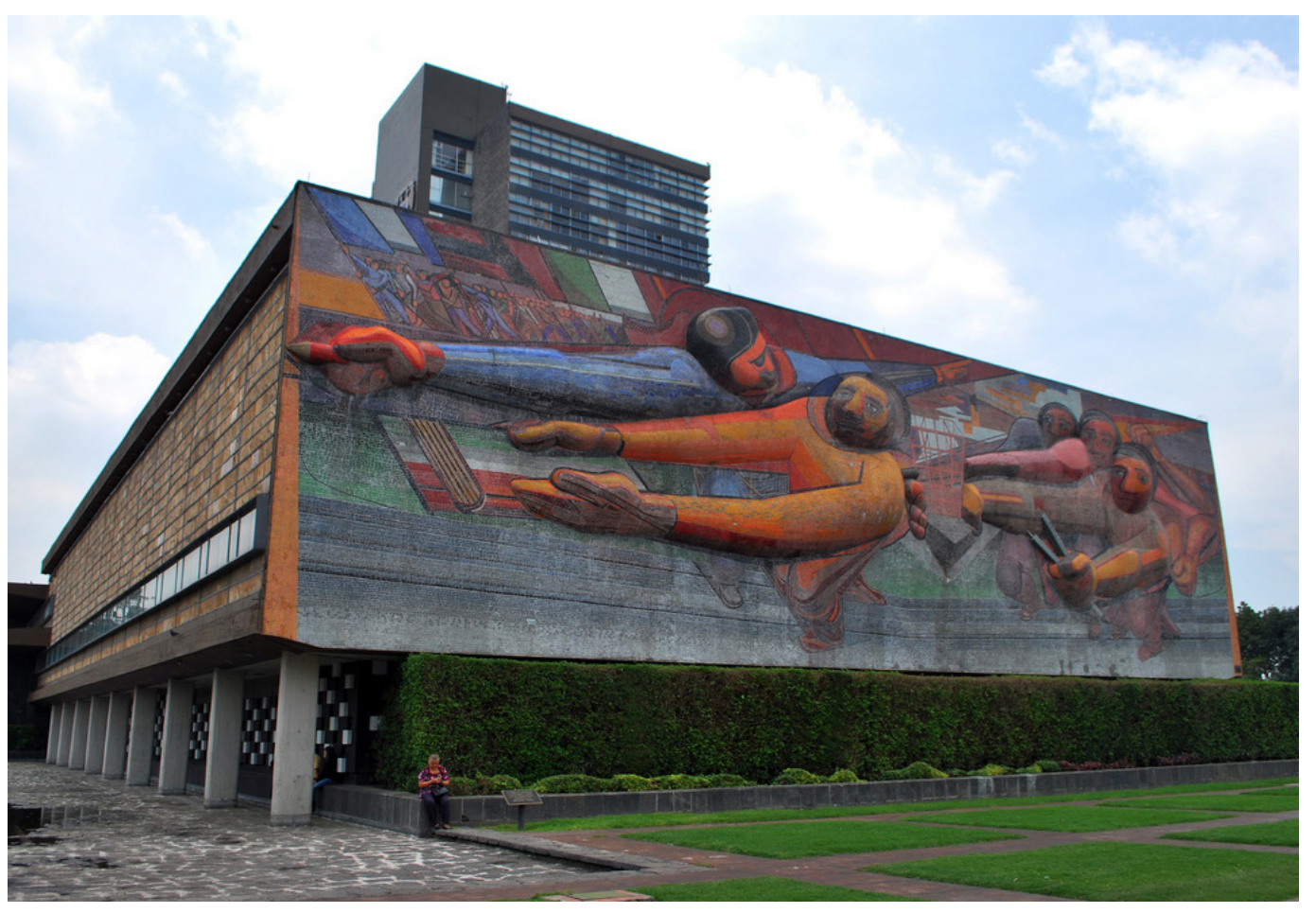



fuentes:

Si quieres saber más sobre el tema, te pueden interesar las siguientes

- Conaculta (s.f.). José Vasconcelos, impulsor de la educación a través del muralismo. Revista de educación y cultura. Recuperado de: http://www.educacionyculturaaz. com/cultura/jose-vasconcelos-impulsor-de-la-educacion-a-traves-del-muralismo.

* Esquivel Hernández, José Luis (2013). Del Ateneo de la Juventud al florecimiento de la cultura. Revista Mexicana de Comunicación. Recuperado de: http://mexicanadecomunicacion.com.mx/rmc/2013/09/26/del-ateneo-de-la-juventud-al-florecimiento-de-la-cultural.

* Jordán, Ximena (2013). El muralismo mexicano: arte, política y educación en un legado estético. Escaner cultural. Revista virtual de arte contemporáneo y nuevas tendencias. 164. Recuperado de: http://revista.escaner.cl/node/7146.

\section{Bibliografía}

* Azuela, Salvador (1980). La aventura vasconcelista 1929. México: Editorial Diana.

- Bernal, María del Carmen (2005). La teoría pedagógica de José Vasconcelos. México: Trillas.

* Cárdenas, Joaquín (1982). José Vasconcelos 1882-1982: Educador político y profeta. México: Ediciones Océano.

* Carreras, Francisco (1970). José Vasconcelos: Filosofía de la coordinación. España: Ediciones Anaya.

* Caso, Antonio (1962). Conferencias del Ateneo de la Juventud. México: UNAM.

* Curiel, Fernando (2001). Ateneo de la Juventud, de la A a la Z. México: UNAM.

* Savín, Francisco (1972). La educación artística en el sistema educativo nacional. Revista de Bellas Artes 1(6), 141-146. México: SEP. Recuperado de https://issuu.com/ cnl-inba/docs/72010106 completo opr

* Vasconcelos, José (2000). Conferencias del Ateneo de la Juventud. México: UNAM.

* Vasconcelos, José (1916). El movimiento intelectual contemporáneo de México. Conferencia leída en la Universidad de San Marcos, Lima, Perú, 26 de julio de 1916.

\section{Cómo citar este artículo}

* Calderón Pichardo, Martha Cecilia (2018). José Vasconcelos. Diferencia y continuidad del proyecto de nación. Revista Digital Universitaria (RDU). Vol. 19, núm. 5 mayo-junio. DOI: http://doi.org/10.22201/codeic.16076079e.2018.v19n5.a8. 